\title{
Drought Stress Enhances Up-Regulation of Anthocyanin Biosynthesis in Grapevine leafroll-associated virus 3-Infected in vitro Grapevine (Vitis vinifera) Leaves
}

\begin{abstract}
Zhen-Hua Cui, State Key Laboratory of Crop Stress Biology for Arid Areas, Key Laboratory of Genetic Improvement of Horticultural Crops of Northwest China, College of Horticulture, Northwest A\&F University, Yangling 712100, Shaanxi, P.R. China; and Department of Viticulture and Enology, University of California, Davis, 95616-3014; Wen-Lu Bi, Xin-Yi Hao, Peng-Min Li, and Ying Duan, State Key Laboratory of Crop Stress Biology for Arid Areas, Key Laboratory of Genetic Improvement of Horticultural Crops of Northwest China, College of Horticulture, Northwest A\&F University, Yangling 712100, Shaanxi, P.R. China; M. Andrew Walker, ${ }^{\dagger}$ Department of Viticulture and Enology, University of California, Davis, 95616-3014; and Yan Xu${ }^{\dagger}$ and Qiao-Chun Wang, ${ }^{\dagger}$ State Key Laboratory of Crop Stress Biology for Arid Areas, Key Laboratory of Genetic Improvement of Horticultural Crops of Northwest China, College of Horticulture, Northwest A\&F University, Yangling 712100, Shaanxi, P.R. China
\end{abstract}

\begin{abstract}
Reddish-purple coloration on the leaf blades and downward rolling of leaf margins are typical symptoms of grapevine leafroll disease (GLD) in redfruited grapevine cultivars. These typical symptoms are attributed to the expression of genes encoding enzymes for anthocyanins synthesis, and the accumulation of flavonoids in diseased leaves. Drought has been proven to accelerate development of GLD symptoms in virus-infected leaves of grapevine. However, it is not known how drought affects GLD expression nor how anthocyanin biosynthesis in virus-infected leaves is altered. The present study used HPLC to determine the types and levels of anthocyanins, and applied reverse transcription quantitative polymerase chain reaction (RT-qPCR) to analyze the expression of genes encoding enzymes for anthocyanin synthesis. Plantlets of Grapevine leafroll-associated virus 3 (GLRaV-3)-infected Vitis vinifera 'Cabernet Sauvignon' were grown in

vitro under PEG-induced drought stress. HPLC found no anthocyaninrelated peaks in the healthy plantlets with or without PEG-induced stress, while 11 peaks were detected in the infected plantlets with or without PEG-induced drought stress, but the peaks were significantly higher in infected drought-stressed plantlets. Increased accumulation of total anthocyanin compounds was related to the development of GLD symptoms in the infected plantlets under PEG stress. The highest level of up-regulated gene expression was found in GLRaV-3-infected leaves with PEG-induced drought stress. Analyses of variance and correlation of anthocyanin accumulation with related gene expression levels found that GLRaV-3infection was the key factor in increased anthocyanin accumulation. This accumulation involved the up-regulation of two key genes, MYBA1 and UFGT, and their expression levels were further enhanced by drought stress.
\end{abstract}

Flavonoids, water-soluble pigments belonging to the large family of phenolic compounds, are the most abundant secondary metabolites and contribute to the development of red, blue, and purple colors in plants (Hichri et al. 2011). Flavonoids also have multiple roles in plant development and defense (Georgiev et al. 2014; Hichri et al. 2011). In grape (Vitis vinifera L.), the flavonoid compounds primarily accumulate in the berry skin of red-fruited cultivars (Kennedy et al. 2001). However, they are also produced in vegetative tissues including leaves at different stages of development (Georgiev et al. 2014; Hichri et al. 2011), and in response to abiotic stress such as drought (Chalker-Scott 1999), high light intensity (Booij-James et al. 2000; Landry et al. 1995), low temperature (Kidd et al. 2001), and biotic stress such as virus infection (Dixon and Paiva 1995; Gutha et al. 2010). Thus, the flavonoid biosynthetic pathway is regulated in a temporal and tissue-specific manner (Chalker-Scott 1999; Georgiev et al. 2014; Hichri et al. 2011).

Anthocyanins in the red-fruited grapevine cultivars are synthesized via the flavonoid pathway. Two classes of genes are required for the synthesis of flavonoids: structural genes that encode enzymes for synthesis of anthocyanin and other flavonoids, and regulatory genes that are involved in spatial and temporal regulation of the structural genes (Deluc et al. 2008). These genes regulate expression of the flavonoid 3-O-glucosyltransferase (UFGT) gene, resulting in

\footnotetext{
${ }^{\dagger}$ Corresponding authors: M. Andrew Walker, awalker@ucdavis.edu; Yan Xu, yan.xu@nwsuaf.edu.cn; and Qiao-Chun Wang: qiaochunwang@nwsuaf. edu.cn
}

Accepted for publication 20 May 2017.

@ 2017 The American Phytopathological Society the conversion of anthocyanidins to anthocyanins by glycosylation (Fig. 1).

Grapevine leafroll-associated virus 3 (GLRaV-3), a single-strand RNA virus in the Closteroviridae family, is one of the causal agents of grapevine leafroll disease (GLD), which severely impacts grapevine production in most of the world's viticultural regions (Maree et al. 2013). Grapevines with GLD have leaves with downwardly rolled leaf margins and chlorotic to reddish-purple coloration with green veins, dependent on whether green- or red-fruited varieties are infected (Maree et al. 2013). These typical symptoms of GLD have been documented to be induced through the de novo synthesis of the two classes of genes encoding the enzymes for anthocyanin synthesis, resulting in the expression of reddish-purple color in virus-infected grapevine leaves (Gutha et al. 2010).

In drought stressed vineyards, red-fruited grapevine cultivars infected by GLD exhibited typical symptoms earlier than wellirrigated ones (Maree et al. 2013; Tanne et al. 1996). Using in vitro cultures, Tanne et al. (1996) found that osmotic stress induced by $4 \%$ sorbitol promoted symptom development in GLRaV-3-infected shoots. We previously reported that the typical symptoms of GLD are easily induced in in vitro GLRaV-3-infected shoots stressed by 4\% PEG (Cui et al. 2015). However, how GLRaV-3 and drought alter the expression of genes in the anthocyanin biosynthesis pathway is poorly understood.

The use of in vitro culture to study the impact of specific biotic and abiotic stress can avoid the confounding impact of other variables such as light, temperature, nutrients, and attack by pathogens (Cui et al. 2015, 2016; Faraloni et al. 2011; Li et al. 2013). The study presented here used HPLC to determine types and levels of anthocyanins, and applied reverse transcription-quantitative realtime polymerase chain reaction (RT-qPCR) to analyze expression of genes that encode the enzymes for anthocyanin synthesis in the GLRaV-3-infected leaves of in vitro grown plantlets of the red-fruited 
grapevine 'Cabernet Sauvignon' (V. vinifera) under PEG-induced drought stress. These experiments were designed to improve our understanding of gene expression responsible for enhanced anthocyanin accumulation in the GLRaV-3-infected grapevine leaves under PEG-induced drought stress.

\section{Materials and Methods}

Plant materials. 'Cabernet Sauvignon' ( $V$. vinifera), a widely grown red wine grape cultivar, was used in this study. The GLRaV-3 variant used in our study was NX-7 (GenBank accession no. KC477154) identified by Liu et al. (2013). The healthy and GLRaV-3-infected in vitro plantlets were established and maintained on a basic medium (BM), as described in our previous publications (Cui et al. 2015, 2016; Hao et al. 2017), in which micrografting was employed to transmit the virus from the single-infected plantlet into healthy plantlets, thus obtaining both the healthy and GLRaV-3-infected samples in the same plant cultivar. Sanitary status of both healthy and infected plant materials was double checked by RT-qPCR, as described below. The healthy and GLRaV-3-infected stock plantlets were then multiplied to produce stock cultures, which were used in the following experiments. BM was composed of halfstrength Murashige and Skoog (1962) medium (MS) supplemented with $30 \mathrm{~g} \mathrm{liter}^{-1}$ sucrose and $7 \mathrm{~g} \mathrm{liter}^{-1}$ agar. The $\mathrm{pH}$ of the medium was adjusted to 5.8 prior to autoclaving at $121^{\circ} \mathrm{C}$ for $20 \mathrm{~min}$. The cultures were maintained at a constant temperature of $24 \pm 2{ }^{\circ} \mathrm{C}$ under a 16-h photoperiod with a light intensity of $50 \mu \mathrm{mol} \mathrm{s}^{-1} \mathrm{~m}^{-2}$ provided by cool-white fluorescent tubes. Subculturing was done every 6 weeks.

Shoot segments $(1.5$ to $2.0 \mathrm{~cm}$ in length containing two fully opened leaves) excised from 6-week-old healthy and GLRaV-3infected stock plantlets were cultured on BM with $4 \%$ (w/v) polyethylene glycol (PEG) 8000, which was shown to induce drought stress in our previous study (Cui et al. 2015, 2016). BM without PEG was used as a control. The cultures were maintained under the same conditions as described above.

Observations on development of symptoms of GLD. Symptoms of GLD were investigated in the diseased in vitro plantlets over 8 weeks of culture.

Anthocyanin analysis by HPLC. Basal leaves harvested from in vitro plantlets at different time points of culture were immediately frozen in liquid nitrogen and then stored at $-80^{\circ} \mathrm{C}$ until analyzed. Separation and subsequent analysis of anthocyanins were carried out according to Chen et al. (2012). Briefly, leaf tissue $(0.5 \mathrm{~g})$ was extracted using $70 \%$ methanol containing $2 \%$ formic acid at $0-4^{\circ} \mathrm{C}$. After centrifugation at $12,000 \mathrm{rpm}$ for $10 \mathrm{~min}$, the supernatant was filtered with a $0.45-\mu \mathrm{m}$ syringe filter prior to HPLC analysis. An HP1200 liquid chromatograph equipped with a diode array detector (Agilent Technology, Palo Alto, CA) was used to separate the anthocyanins. The Inertsil ODS-3 column (5.0 $\mu \mathrm{m}$ particle size, $4.6 \mathrm{~mm} \times 250 \mathrm{~mm}$; GL Sciences Inc., Tokyo, Japan) preceded by an Inertsil ODS-3 Guard Column $(5.0 \mu \mathrm{m}, 4.0 \mathrm{~mm} \times$ $10 \mathrm{~mm}$ ) was used as a separator. Solvent A consisted of $10 \%$ formic acid (11.36\% of $88 \%$ formic acid) dissolved in water and solvent B contained $10 \%$ formic acid (11.36\% of $88 \%$ formic acid) and $1.36 \%$ water in acetonitrile (HPLC grade, purity: $99.9 \%$ ). The gradient was $95 \%$ A with 5\% B (0 min), 85\% A with $15 \%$ B (25 min), $78 \%$ A with $22 \%$ B (42 min), $64 \%$ A with $36 \%$ B (60 min), and $95 \%$ A with $5 \%$ B (65 min). The postrun time was $10 \mathrm{~min}$, and the flow rate was $1.0 \mathrm{ml} \mathrm{min}^{-1}$ at $30^{\circ} \mathrm{C}$. Anthocyanins were monitored at $520 \mathrm{~nm}$ wavelength. Delphinidin-3glucoside, cyanidin-3-glucoside, petunidin-3-glucoside, peonidin-3glucoside, and malvidin-3-glucoside were identified by comparison of retention time and UV spectra with authentic standards (St. Louis, MO), and quantified with their respective standard curves with linear correlation coefficients greater than 0.999. Other components were putatively identified according to the retention time and UV spectra

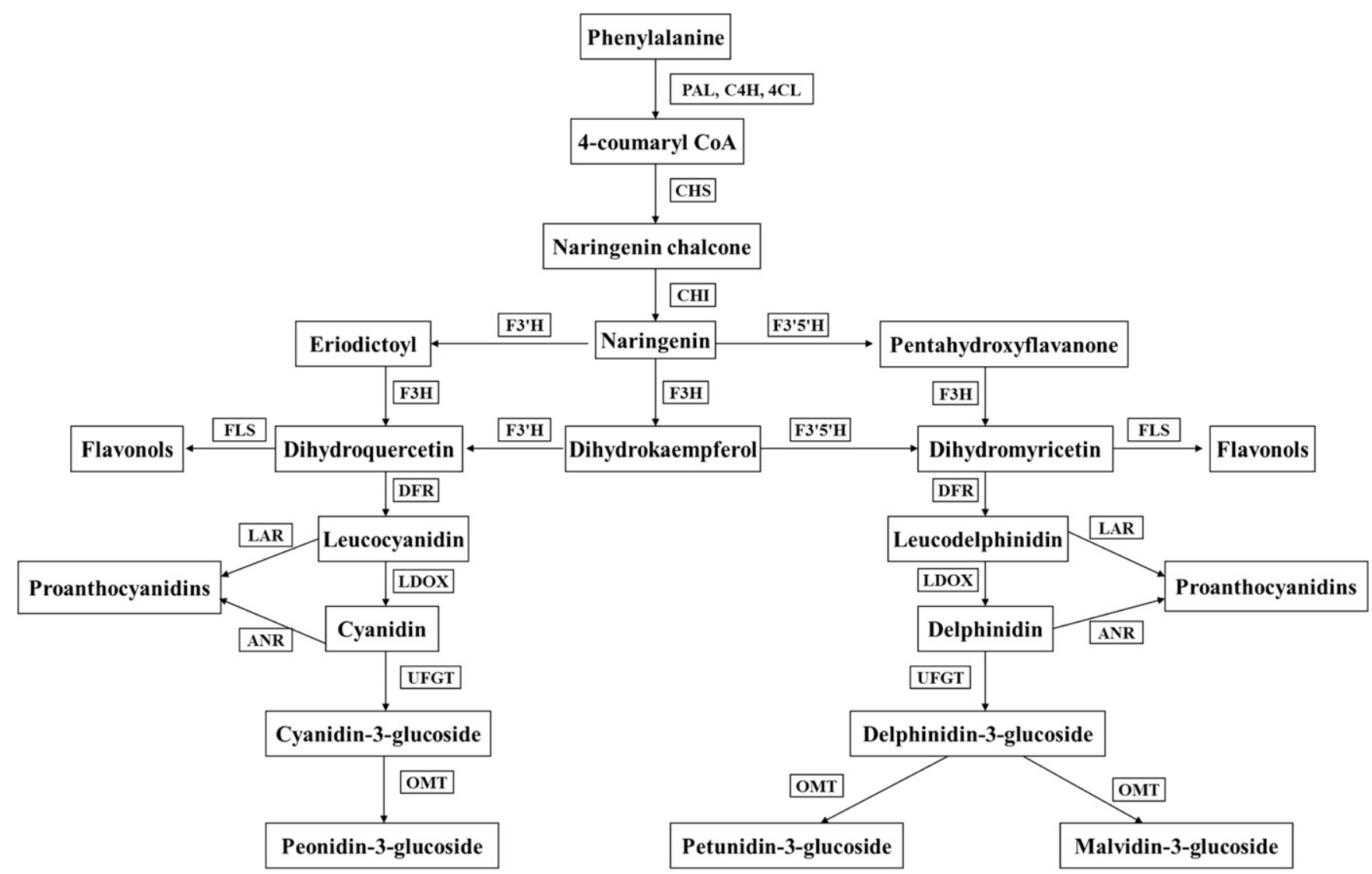

Fig. 1. Biosynthetic pathway of flavonoids. PAL, phenylalanine ammonia-lyase; $\mathrm{C} 4 \mathrm{H}$, cinnamate-4-hydroxylase; $4 \mathrm{CL}$, 4-coumarate: CoA ligase; $\mathrm{CHS}$, chalcone synthase; $\mathrm{CHI}$ chalcone isomerase; F3'H, flavonoid-3'-hydroxylase; F3'5'H, flavonoid-3',5'-hydroxylase; F3H, flavanone-3-hydroxylase; FLS, flavonol synthase; DFR, dihydroflavonol reductase; LDOX, leucoanthocyanidin dioxygenase; LAR, leucoanthocyanidin reductase; ANR, anthocyanidin reductase; UFGT, UDP-glucose:flavonoid 3-0-glucosyltransferase; OMT, O-methyltransferase (based on data of Gould and Lister 2006; Holton and Cornish 1995; Koes et al. 2005; Winkel-Shirley 2001). 
and their concentrations were expressed as malvidin-3-glucoside equivalents.

RNA isolation and cDNA synthesis. Total RNA was extracted from basal leaves $(0.5 \mathrm{~g})$ using Trizol Reagent (Invitrogen Ltd., Carlsbad, CA), according to the manufacturer's instructions. RNA quality was evaluated by both optical density (OD) value (1.9 to 2.1) at 260/280 nm (NanoDrop 2000C, Thermo Scientific) and electrophoresis in a $1.5 \%$ agarose gel with sharp, clear $28 \mathrm{~s}$ and $18 \mathrm{~s}$ rRNA bands stained by ethidium bromide. cDNA was synthesized using reagent kits (RR047A, Takara, Japan). Briefly, $1 \mu \mathrm{g}$ of total RNA was used for gDNA removal in a $10 \mu \mathrm{l}$ mix with other additions of $2 \mu \mathrm{l}$ of $5 \times$ gDNA eraser buffer, $1 \mu \mathrm{l}$ of gDNA eraser, and RNase free water at $42^{\circ} \mathrm{C}$ for $2 \mathrm{~min}$. A $10 \mu \mathrm{l}$ master mix including $4 \mu \mathrm{l}$ of $5 \times$ PrimeScript buffer, $1 \mu l$ of PrimeScript RT enzyme mix, $1 \mu$ l of RT primer mix (including Oligo dT primer and random hexamers), and $4 \mu \mathrm{l}$ of RNase free water were added to the reaction solution from last step, followed by an incubation at $37^{\circ} \mathrm{C}$ for $15 \mathrm{~min}$ and $85^{\circ} \mathrm{C}$ for $5 \mathrm{~s}$ All the cDNAs were diluted by five times for $\mathrm{qPCR}$ analysis.

PCR and primer specificity analysis. All the primers of anthocyanin biosynthesis pathway genes and the reference gene (NAD5) were selected from past studies with identified high specificity and amplification efficiency (Table 1). PCR was carried out using reagent kits (RR001A, Takara, Japan) in a $50 \mu$ reaction system containing $5 \mu l$ of $10 \times$ Ex Taq buffer ( $\mathrm{Mg}^{2+}$ plus), $4 \mu \mathrm{l}$ of dNTP mixture, $0.25 \mu \mathrm{l}$ of Ex Taq, $5 \mu \mathrm{l}$ of each primer $(10 \mu \mathrm{M}), 10 \mu \mathrm{l}$ of cDNA, and $20.75 \mu \mathrm{l}$ of water. The reactions were performed with an initial temperature of $50^{\circ} \mathrm{C}$ for $5 \mathrm{~min}$, followed by 35 cycles of $94^{\circ} \mathrm{C}$ for $30 \mathrm{~s}, 56^{\circ} \mathrm{C}$ for $45 \mathrm{~s}$, and $72^{\circ} \mathrm{C}$ for $30 \mathrm{~s}$, with a final extension at $72^{\circ} \mathrm{C}$ for $5 \mathrm{~min}$. Electrophoresis was run with the PCR products in a $2 \%$ agarose gel. PCR products were purified using ExoSAP-IT (product no. 78200, Affymetrix, USB) and then sequenced in both orientations by ABI Prism 3730 Genetic Analyzer at UCDNA Sequencing Facility, University of California, Davis, CA. The sequencing results were compared with corresponding sequences in GenBank by a BLAST analysis (https://blast. ncbi.nlm.nih.gov/Blast.cgi?PROGRAM=blastn\&PAGE_TYPE= BlastSearch\&LINK_LOC=blasthome).

qPCR and qPCR efficiency analysis. The GLRaV-3 was quantified using the primer of Bester et al. (2014) (forward/reverse: GGGRACGGARAAGTGTTACC/TCCAAYTGGGTCATRCACAA), and 18S ribosomal RNA of grapevine was used as the reference gene (forward/reverse: GTGACGGAGAATTAGGGTTCGA/CTGCCTTC CTTGGATGTGGTA, Osman and Rowhani 2006). qPCRs were run on an IQ5 machine (BIO-RAD, U.S.A.) using reagent kits (RR820A, Takara, Japan) in a $20 \mu \mathrm{l}$ reaction mixture containing $10 \mu \mathrm{l}$ of SYBR Premix Ex Taq, $0.8 \mu \mathrm{l}$ of each primer $(10 \mu \mathrm{M}), 2 \mu \mathrm{l}$ of fivefold diluted cDNA, and $6.4 \mu \mathrm{l}$ of sterile water. The following program was used for all qPCR analysis: an initial denaturation step at $94^{\circ} \mathrm{C}$ for $30 \mathrm{~s}, 45$ cycles of $94^{\circ} \mathrm{C}$ for $10 \mathrm{~s}, 56^{\circ} \mathrm{C}$ for $10 \mathrm{~s}$, and $72^{\circ} \mathrm{C}$ for $30 \mathrm{~s}$. A melting curve analysis was carried out over the range 65 to $97^{\circ} \mathrm{C}$ to verify the specificity of amplicons. Two controls of no-RT and no-template were included. The transcript levels of each gene were normalized according to the reference gene, using the $2^{-\triangle \triangle \mathrm{Cq}}$ method (Livak and Schmittgen 2001), where $\mathrm{Cq}$ is the number of cycles needed for the fluorescence signal to reach a specific threshold level of detection and is inversely correlated with the

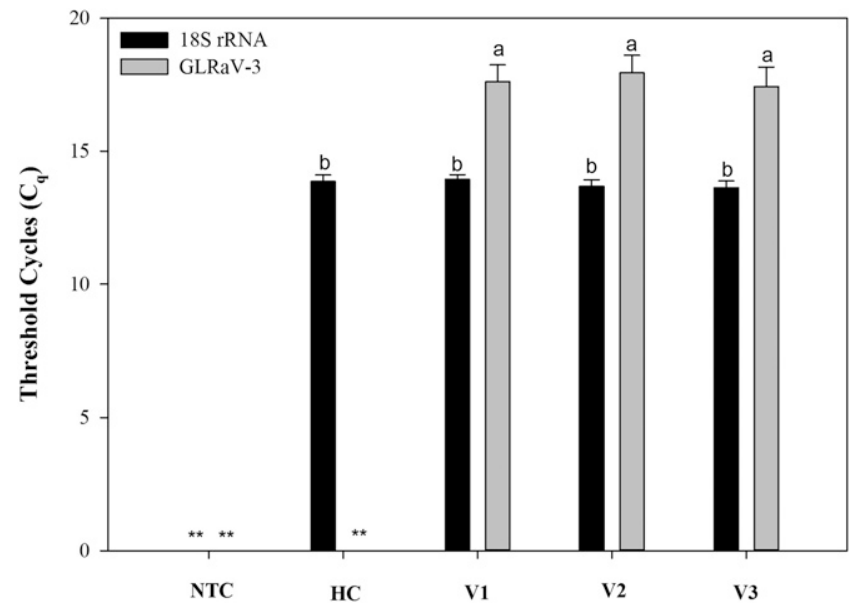

Fig. 2. Analysis of GLRaV-3 concentration by RT-qPCR of the in vitro stock plantlets of 'Cabernet Sauvignon' grapevine (Vitis vinifera) before used in the following experiments. NTC $=$ no template control; $\mathrm{HC}=$ healthy samples; $\mathrm{V} 1, \mathrm{~V} 2$, and $\mathrm{V} 3=$ GLRaV-3-infected samples of three repeats. ${ }^{* *}$ means $\mathrm{Cq}$ was undetectable. Data are presented as means $\pm \mathrm{SE}$, and different letters indicate significant differences at $P \leq 0.05$

Table 1. Primers used for RT-qPCR analysis of anthocyanin biosynthesis

\begin{tabular}{|c|c|c|c|c|}
\hline Primer names & Reference & Primer sequence $5^{\prime}-3^{\prime}$ (forward/reverse) & PN40024 12X V2 IDa & Coordinates $^{\mathbf{a}}$ \\
\hline NAD5 & Menzel et al. 2002 & $\begin{array}{l}\text { GATGCTTCTTGGGGCTTCTTGTT/ } \\
\text { CTCCAGTCACCAACATTGGCATAA }\end{array}$ & GU585873 & Unknown \\
\hline CHS2 & Goto-Yamamoto et al. 2002 & $\begin{array}{l}\text { TCTGAGCGAGTATGGGAACA/ } \\
\text { AGGGTAGCTGCGTAGGTTGG }\end{array}$ & VIT_214s0068g00920 & chr14:24673233..24688859 \\
\hline CHS3 & Gutha et al. 2010 & $\begin{array}{l}\text { TCACTTGGACAGCCTTGTTG/ } \\
\text { CAATTCGAACATGGGCTTCT }\end{array}$ & VIT_205s0136g00260 & chr5:13597238..13599692 \\
\hline CHI1 & Jeong et al. 2004 & $\begin{array}{l}\text { CAGGCAACTCCATTCTTTTC/ } \\
\text { TTCTCTATCACTGCATTCCC }\end{array}$ & VIT_213s0067g03820 & chr13:2162234..2164431 \\
\hline $\mathrm{F}^{\prime}{ }^{\mathrm{H}}$ & Castellarin et al. 2006 & $\begin{array}{l}\text { ATTCGCCACCCTGAAATGAT/ } \\
\text { AGCCGTTGATCTCACAGCTC }\end{array}$ & VIT_217s0000g07200 & chr17:8011519..8014480 \\
\hline $\mathrm{F}^{\prime} 5^{\prime} \mathrm{H}$ & Castellarin et al. 2006 & $\begin{array}{l}\text { GAAGTTCGACTGGTTATTAACAAAGAT/ } \\
\text { AGGAGGAGTGCTTTAATGTTGGTA }\end{array}$ & VIT_206s0009g02810 & chr6:15670201..15671940 \\
\hline $\mathrm{F} 3 \mathrm{H} 1$ & Jeong et al. 2004 & $\begin{array}{l}\text { CCAATCATAGCAGACTGTCC/ } \\
\text { TCAGAGGATACACGGTTGCC }\end{array}$ & VIT_204s0023g03370. & chr4:19929438..19931447 \\
\hline $\mathrm{F} 3 \mathrm{H} 2$ & Jeong et al. 2004 & $\begin{array}{l}\text { CTGTGGTGAACTCCGACTGC/ } \\
\text { CAAATGTTATGGGCTCCTCC }\end{array}$ & VIT_218s0001g14310 & chr18:12302766..12306068 \\
\hline DFR & Jeong et al. 2004 & $\begin{array}{l}\text { GAAACCTGTAGATGGCAAGA/ } \\
\text { GGCCAAATCAAACTACCAGA }\end{array}$ & VIT_218s0001g12800 & chr18:10907364..10910253 \\
\hline LDOX & Jeong et al. 2004 & $\begin{array}{l}\text { AGGGAAGGGAAAACAAGTAG/ } \\
\text { ACTCTTTGGGGATTGACTGG }\end{array}$ & VIT_202s0025g04720 & chr2:4282027..4284085 \\
\hline UFGT & Jeong et al. 2004 & $\begin{array}{l}\text { GGGATGGTAATGGCTGTGG/ } \\
\text { ACATGGGTGGAGAGTGAGTT }\end{array}$ & VIT_216s0039g02230 & chr16:2332463..2334702 \\
\hline MybA1 & Jeong et al. 2004 & $\begin{array}{l}\text { TAGTCACCACTTCAAAAAGG/ } \\
\text { GAATGTGTTTGGGGTTTATC }\end{array}$ & VIT_202s0033g00410 & chr2:14239584..14240983 \\
\hline
\end{tabular}


amount of template nucleic acid present in the reaction. qPCR efficiency of each gene was analyzed with five-point dilutions of cDNA $(1: 1,1: 4,1$ : $16,1: 64$, and 1:256). The slope $(\mathrm{m})$ of the line was determined by plotting the $\mathrm{Cq}$ (y-axis) versus log cDNA dilution (x-axis). qPCR efficiency was then calculated using the equation $E=\left(10^{[-1 / \mathrm{m}]}-1\right) \times 100$, where $E$ is the qPCR efficiency and $\mathrm{m}$ is the slope.

Experimental design and data analysis. All experiments were conducted in a completely randomized design. Five biological replicates were included in every treatment and all experiments were repeated three times. Statistical analysis of the data were performed with the SPSS-19 for Windows statistics software package. Significant differences among means were analyzed by one-way ANOVA with the least significant difference (LSD) at $P \leq 0.05$. Two-way
ANOVA and MANOVA, including GLRaV-3 infection and drought as factors, were performed to analyze the combined effects of these two factors on anthocyanin accumulation and on related gene expression, respectively. Significant differences were analyzed with LSD at $P \leq 0.05$ or $P \leq 0.01$. Analysis with Spearman's correlation was done to select the pivotal genes contributing to the development of GLD symptoms in the present experimental system.

\section{Results}

GLRaV-3 concentration of the infected stock plantlets. All of our GLRaV-3-infected plantlets were established from the same source plant and were maintained under constant conditions, and they showed similar high levels of GLRaV-3 concentration (Fig. 2).

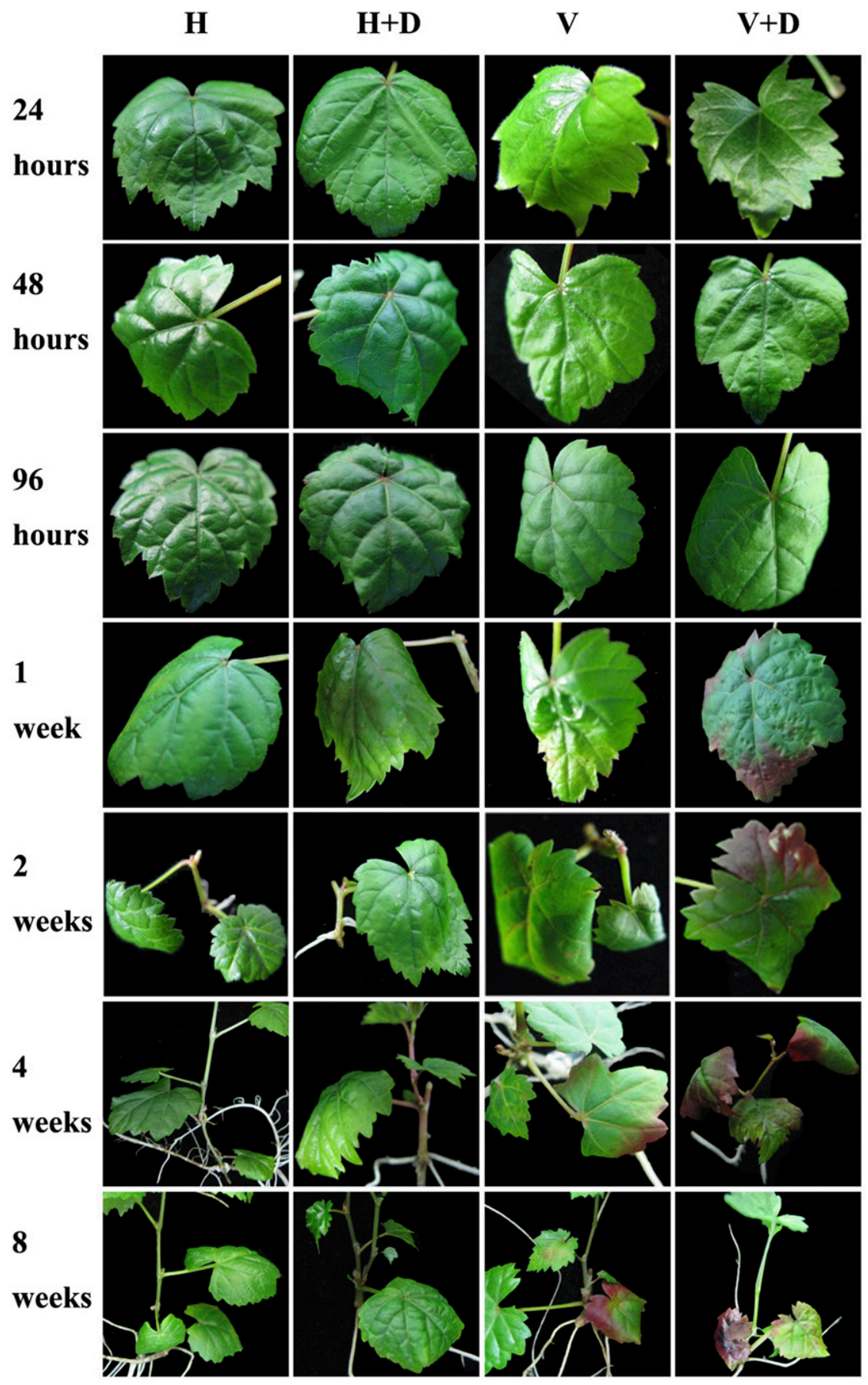

Fig. 3. Development of GLRaV-3 symptoms in the basal leaves of in vitro plantlets of 'Cabernet Sauvignon' grapevine (Vitis vinifera) stressed with PEG-induced drought at different time points of culture. $\mathrm{H}=$ healthy plantlets without $P E G$ stress; $H+D=$ healthy plantlets with $4 \% P E G$ stress; $V=$ virus-infected plantlets without $P E G$ stress; $V+D=$ virus-infected plantlets with $4 \%$ PEG stress. 
Virus was undetectable in the healthy plantlets (Fig. 2), which was also confirmed by RT-PCR (Cui et al. 2015). The results indicated that the virus status was stable in the in vitro stock plantlets used in the present study.

Symptom development of GLD. None of the leaves from healthy in vitro plantlets displayed any reddish coloration during the 8 weeks of culture with or without PEG stress, although the leaves with PEG stress did start to show light chlorosis after 1 week in culture compared with the leaves without PEG stress (Fig. 3). After 2 weeks of culture, the GLRaV-3 infected in vitro plantlets grown without PEG stress began to show the downward leaf rolling symptom of GLD (Fig. 3). Red coloration was observed after 4 weeks of culture and became obvious after 8 weeks of culture (Fig. 3). When stressed by $4 \%$ PEG, about $10 \%$ (data not shown) of the virus-infected in vitro plantlets began to show reddened basal leaves after $96 \mathrm{~h}$ of culture. Downward leaf rolling and reddish coloration became obvious after 1 to 4 weeks of culture (Fig. 3).

Anthocyanin analysis by HPLC. Anthocyanin chromatograms analyzed by HPLC in the healthy and infected plantlets without
Table 2. Identified anthocyanin compounds in leaves of GLRaV-3 infected in vitro plantlets of 'Cabernet Sauvignon' grapevine (Vitis vinifera) after 8 weeks of culture, as shown in Figure 4

\begin{tabular}{lcl}
\hline Peaks & Retention time (min) & \multicolumn{1}{c}{ Compounds } \\
\hline 1 & 15.10 & Delphinidin-3-glucoside $^{\mathrm{a}}$ \\
2 & 18.76 & Cyanidin-3-glucoside $^{\mathrm{a}}$ \\
3 & 21.92 & Petunidin-3-glucoside $^{\mathrm{a}}$ \\
4 & 25.84 & Peonidin-3-glucoside $^{\mathrm{a}}$ \\
5 & 28.43 & Malvidin-3-glucoside $^{\mathrm{a}}$ \\
6 & 35.35 & Petunidin-3-(6-acetyl)-glucoside $^{\mathrm{b}}$ \\
7 & 42.53 & Malvidin-3-(6-acetyl)-glucoside $^{\mathrm{b}}$ \\
8 & 44.65 & Cyanidin-3-(6-p-coumaroyl)-glucoside $^{\mathrm{b}}$ \\
9 & 47.03 & Petunidin-3-(6-p-coumaroyl)-glucoside \\
10 & 52.75 & Peonidin-3-(6-p-coumaroyl)-glucoside \\
11 & 53.66 & Malvidin-3-(6-p-coumaroyl)-glucoside $^{\mathrm{b}}$ \\
\hline
\end{tabular}

${ }^{a}$ Components were identified by comparison of retention time and UV spectra with authentic standards.

${ }^{\mathrm{b}}$ Other components were putatively identified according to the retention time and UV spectra.

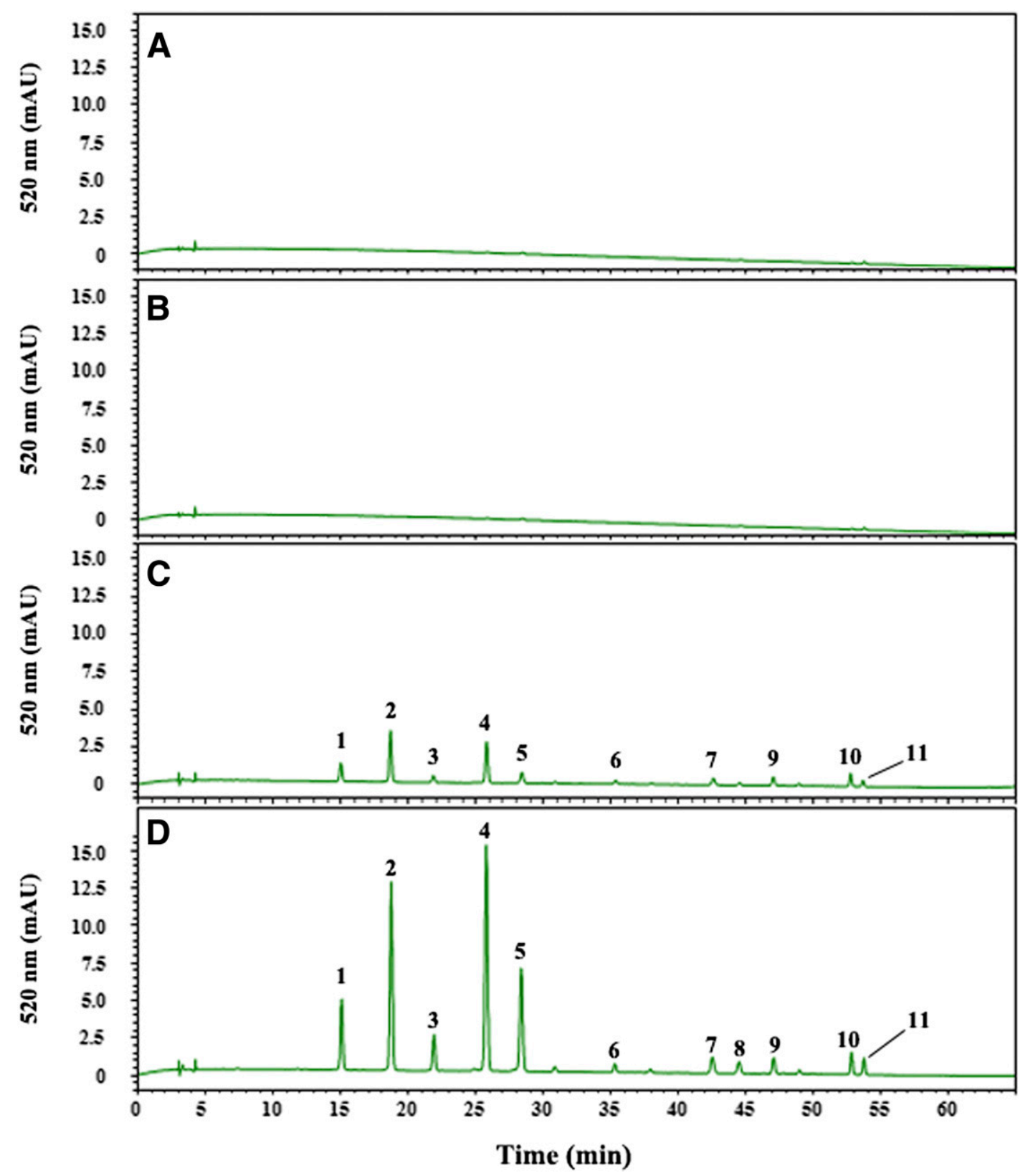

Fig. 4. Anthocyanin chromatograms by HPLC in leaves of healthy plantlets without PEG stress (A), healthy plantlets with $4 \%$ PEG stress (B), GLRaV-3-infected plantlets without PEG stress (C), and GLRaV-3-infected plantlets with 4\% PEG stress (D) of in vitro plantlets of 'Cabernet Sauvignon' grapevine (Vitis vinifera) after 8 weeks of culture; the numbers 1 to 11 indicate different categories of anthocyanin displayed in Table 2. 
and with PEG stress are shown in Figure 4. No peaks were revealed in the healthy plantlets with or without PEG stress (Fig. 4A and B). In total, 11 peaks were detected in the infected plantlets (Fig. 4C and D). When the diseased plants with and without PEG stress were compared, peaks 1 to 5 were distinctly higher with 4\% PEG. Red coloration implied anthocyanin accumulation, which prompted the identification of the compounds corresponding to the 11 peaks (Table 2). Concentrations of total anthocyanins in the healthy and infected plantlets grown with and without PEG stress were calculated and shown in Figure 5. Almost no anthocyanin was found in the healthy plantlets grown with or without PEG stress during 8 weeks of culture. In the infected plantlets grown without PEG stress, anthocyanin levels were low during the first 2 weeks of culture, noticeably increased after 4 weeks, and continued to increase through the 8 weeks of culture (Fig. 5). In the infected plantlets grown with $4 \%$ PEG stress, anthocyanin levels started to increase after only $96 \mathrm{~h}$ of culture, and then rapidly increased at 4 through 8 weeks of culture (Fig. 5). Total anthocyanin content was significantly higher in the infected plantlets grown with 4\% PEG than those grown without PEG at each of the corresponding culture points (Fig. 5): 2.0 times at 96 h, 2.3 at 1 week, 3.0 at 2 weeks, 3.2 at 4 weeks, and 6.1 times at 8 weeks of culture, respectively. A two-way ANOVA was used to evaluate the effects of GLRaV-3 and drought stress on anthocyanin concentrations (Table 3). The large F-test value and very low significance level ( $P$-value) of the corrected model indicated that the model we used accounted for the variance of anthocyanin contents. GLRaV-3 infection and drought stress, as well as their combination, had significant effects $(P \leq 0.01)$ on the anthocyanin accumulation. It was also notable that GLRaV-3 infection exerted a greater (much larger F-value) effect on anthocyanin accumulation in the model than drought did. The significant effect of drought stress on anthocyanin content almost all came from the interaction with GLRaV-3 infection (very similar F-value of drought and virus-drought). The partial eta-squared values of sources (close to 1 ) showed that almost
$100 \%$ of the dependent variable variance (anthocyanin content) could be explained by the independent variables (Table 3).

Primer specificity, qPCR efficiency, and expression stability of the reference gene (NAD5). All the primers used for qPCR showed a single peak in the melting curve for each amplicon (data not shown). A band with expected size of each amplicon was separated by electrophoresis in agarose gel without a visible primer-dimer (Fig. 6). Sequencing results of each gene showed high levels of similarity (97 to $100 \%$ ) with corresponding gene sequence in GenBank. All qPCRs displayed an efficiency between 98 and $100 \%$. NAD5 was selected for the reference gene in our study due to its good expression stability identified under GLRaV-3-infected field conditions (Gutha et al. 2010). In our in vitro experimental conditions, NAD5 showed a highly stable expression level among the different treatments (Fig. 7). The medians of their $\mathrm{Cq}$ among the treatments were similar (Fig. 7).

Gene expressions of anthocyanin biosynthesis pathway. Expression of 10 structural genes (CHS2, CHS3, CHI1, F3'H, F3' 5'H, F3H1, F3H2, DFR, LDOX, UFGT) and one regulatory gene (MYBA1) involved in the anthocyanin biosynthesis pathway were investigated at different time points of culture (Fig. 8). Two

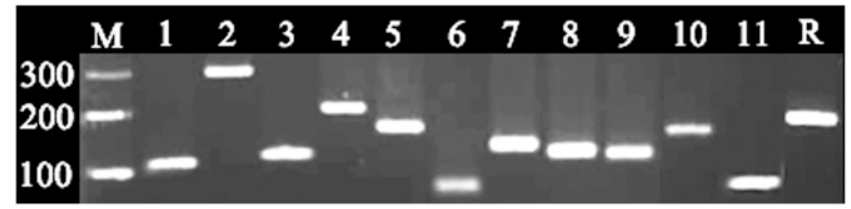

Fig. 6. Specificity test of the primers used to amplify the genes of anthocyanin biosynthesis pathway by RT-PCR. M = marker, R = reference gene (NAD5), and numbers 1 to 11 identify the genes of $\mathrm{CHI} 1, \mathrm{CHS} 2, \mathrm{CHS} 3, \mathrm{~F}^{\prime} \mathrm{H}, \mathrm{F}^{\prime} \mathrm{5}^{\prime} \mathrm{H}, \mathrm{F} 3 \mathrm{H} 1$, F3H2, DFR, LDOX, UFGT, and MYBA1, respectively.

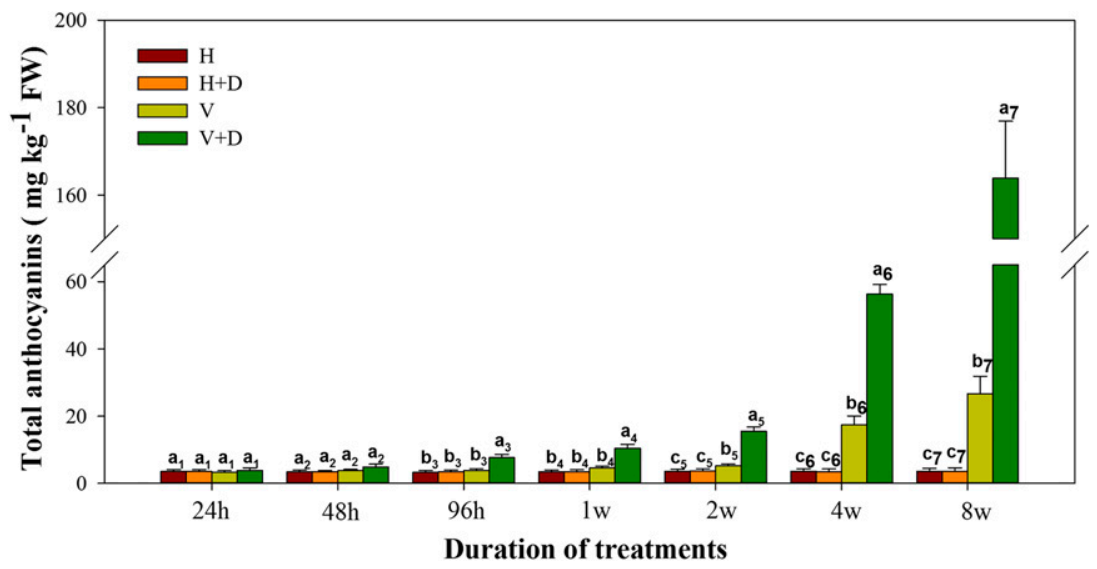

Fig. 5. Anthocyanin levels in leaves of healthy and GLRaV-3-infected in vitro plantlets of 'Cabernet Sauvignon' grapevine (Vitis vinifera) at different time points of culture. Healthy plantlets without PEG stress $(\mathrm{H})$ and with $4 \%$ PEG stress $(\mathrm{H}+\mathrm{D})$. GLRaV-3-infected plantlets without PEG stress $(\mathrm{V})$ and with $4 \%$ PEG stress $(\mathrm{V}+\mathrm{D})$. Data are presented as means $\pm \mathrm{SE}$; those with different letters within the same time of analysis are significantly different at $P \leq 0.05$.

Table 3. Two-way ANOVA of effects of GLRaV-3 and PEG-induced drought stress on anthocyanin levels in leaves of in vitro plantlets of 'Cabernet Sauvignon' grapevine (Vitis vinifera) after 8 weeks of culture

\begin{tabular}{|c|c|c|c|c|c|c|}
\hline Source & Sum of squares & df & Mean square & $\mathbf{F}$ & $\mathbf{P a}^{\mathbf{a}}$ & Partial eta squared \\
\hline Corrected model & 89,123 & 3 & 29,710 & 1,941 & $* *$ & 0.997 \\
\hline Intercept & 48,817 & 1 & 48,817 & 3,189 & $* *$ & 0.995 \\
\hline Virus & 42,088 & 1 & 42,088 & 2,749 & $* *$ & 0.994 \\
\hline Drought & 23,514 & 1 & 23,514 & 1,536 & $* *$ & 0.990 \\
\hline Virus-drought & 23,529 & 1 & 23,529 & 1,537 & $* *$ & 0.990 \\
\hline Error & 245 & 16 & 15.3 & & & \\
\hline Total & 138,194 & 20 & & & & \\
\hline Corrected total & 89,377 & 19 & & & & \\
\hline
\end{tabular}

a $* *=$ Significant differences at $P \leq 0.01$; adjusted $\mathrm{R}^{2}=0.997$. 


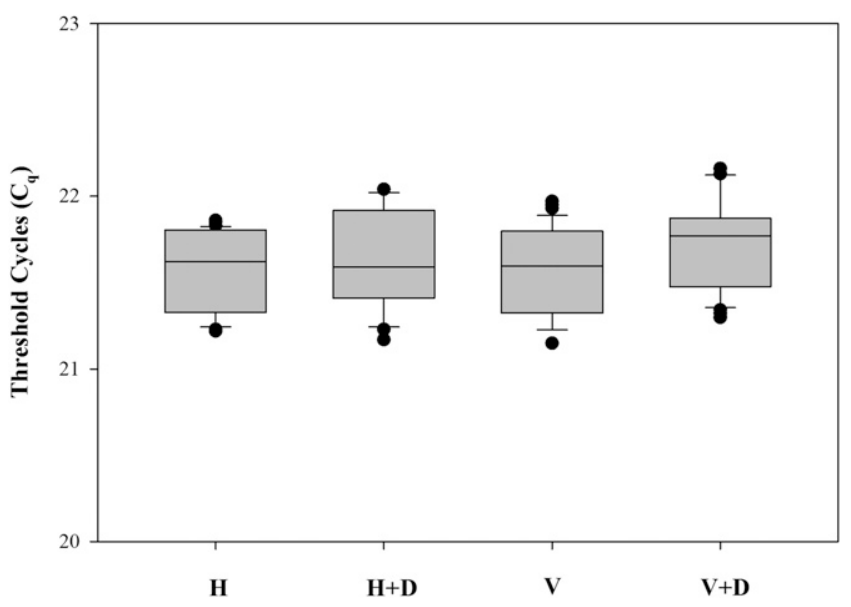

Fig. 7. Analysis of the expression stability of reference gene (NAD5) by RT-qPCR in in vitro plantlets of 'Cabernet Sauvignon' grapevine (Vitis vinifera) of four different treatments during the whole culture. Gray bars indicate the $25 / 75$ percentiles, whisker caps indicate the 10/90 percentiles, the horizontal line inside each box represents the median and all outliers are indicated by dots. $\mathrm{H}=$ healthy plantlets without $\mathrm{PEG}$ stress; $\mathrm{H}+\mathrm{D}=$ healthy plantlets with $4 \%$ PEG stress; $\mathrm{V}=\mathrm{GLRaV}$-3-infected plantlets without PEG stress; $V+D=G L R a V-3$-infected plantlets with $4 \%$ PEG stress. expression patterns of the 11 genes were found: in the first group (CHS2, CHS3, CHI1, F3'H, F3'5'H, F3H1, F3H2, DFR, LDOX), gene expression increased and then decreased, indicating an early triggered pattern prior to anthocyanin accumulation. In the second group (UFGT, MYBA1), gene expression progressively increased. Expression of all 11 genes was significantly up-regulated in the GLRaV-3-infected plantlets with or without PEG and the healthy with PEG treatments compared with the healthy without PEG stress from $24 \mathrm{~h}$ to 8 weeks in varying degrees (Fig. 8). Overall, the highest level of up-regulated gene expression was found in the virus-infected plantlets with the 4\% PEG stress treatment (Fig. 8). This treatment also accumulated the highest levels of anthocyanin (Figs. 4 and 5). Compared with the virus-infected plantlets without PEG stress treatment, the peak levels of expression for CHS2, F3'H, F3H1, F3H2, and DFR in the healthy treatment with PEG stress were higher at several time points. However, UFGT and MYBA1 expression in the virus-infected without PEG stress treatment, was significantly higher than the healthy with PEG stress treatment after $24 \mathrm{~h}$ of culture and continued increasing throughout the 8 weeks of culture (Fig. 8). After 8 weeks of culture, the expression levels of UFGT in the virus infected plantlets without PEG stress and the infected with PEG stress was, respectively, 36 and 63 times higher than those of the healthy without PEG stress treatment. The same pattern was also observed in MYBA1 expression with 29 and 71 times higher values, respectively
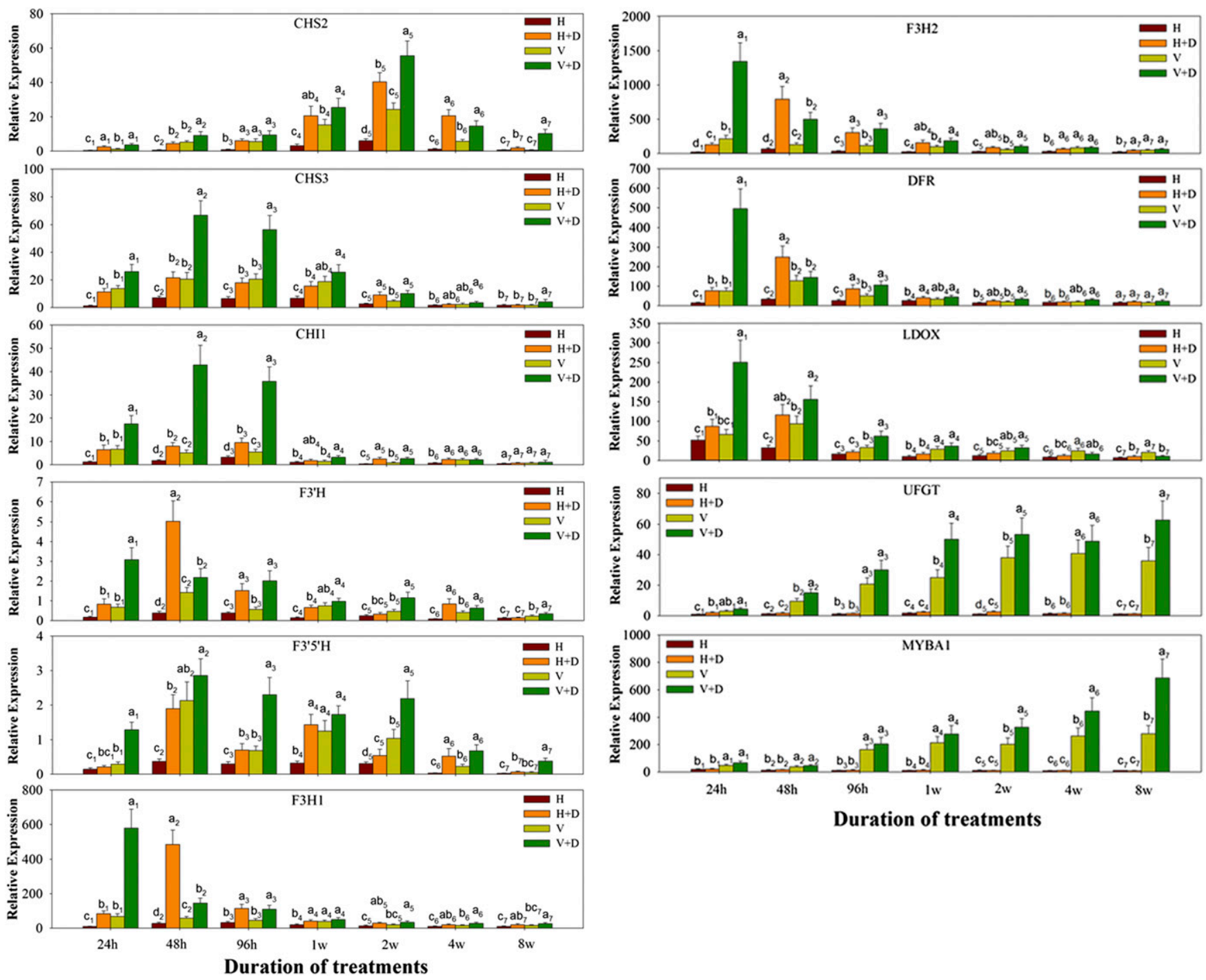

Duration of treatments

Fig. 8. Relative expression of the anthocyanin biosynthetic genes by RT-qPCR in leaves of in vitro plantlets of 'Cabernet Sauvignon' grapevine (Vitis vinifera) at different time points of culture. $\mathrm{H}=$ healthy plantlets without PEG stress; $\mathrm{H}+\mathrm{D}=$ healthy plantlets with $4 \% \mathrm{PEG}$ stress; $\mathrm{V}=\mathrm{GLRaV}$-3-infected plantlets without $P E G$ stress; $V+D=G L R a V-3$-infected plantlets with $4 \% \mathrm{PEG}$ stress. Data were presented as means $\pm \mathrm{SE}$; those with different letters within the same time of analysis are significantly different at $P \leq 0.05$. 
(Fig. 8). It was noteworthy that the expression of UFGT and MYBA1 in the healthy with 4\% PEG stress treatment was about the same as the healthy without PEG stress treatment during the 8 weeks culture period (Fig. 8), while other genes had different expression patterns (Fig. 8). Moreover, a two-way MANOVA using four different criteria of test statistics (Pillai's trace, Wilks' lambda, Hotelling's trace, and Roy's largest root) was conducted to detect the effects of GLRaV-3 infection and drought stress on expression levels of the investigated genes (Table 4). Pillai's trace value (close to 1 in all effects), Wilks' Lambda value (close to 0 in all effects), and partial eta-squared (close to 1 in all effects) indicated that the independent variables accounted for almost $100 \%$ of the variance of the gene expression levels of the 11 genes in our model. The significance level values ( $P$-values), which were associated with the F-values (Hotelling's trace and Roy's largest values were analogous to F-value), hypothesis, and error degrees of freedom, showed the significant effects of GLRaV-3-infection, drought stress, and their interaction on the expression levels of the investigated genes (Table 4).

Correlation analysis of the gene expressions and anthocyanin accumulation. Since the expression level of the genes involved in the biosynthesis pathway directly affect anthocyanin accumulation, a correlation analysis of gene expression levels and anthocyanin accumulation at different time points was performed to select the pivotal genes contributing to the anthocyanin accumulation in the present experimental system (Table 5). Anthocyanin content was positively correlated at $P \leq 0.01$ level only with UFGT and MYBA1 expression levels. The expression level of MYBA1 was significantly correlated at the $P \leq 0.01$ level only with UFGT (Table 5). The genes with the same expression pattern (initially increased and then decreased, Fig. 8) all had significant positive correlations with each other except CHS2.

\section{Discussion}

Anthocyanin biosynthesis has been comprehensively studied from pre-veraison to post-veraison in grapevine berries. Mori et al. (2007) and Yamane et al. (2006) found that high temperature adversely affects anthocyanin accumulation in berry skin. Moderate drought stress has also been found to be a significant factor in increasing the anthocyanin content of grape berries (Berdeja et al. 2014; Bucchetti et al. 2011; Intrigliolo et al. 2012; Ollé et al. 2011; Roby et al. 2004; Santesteban et al. 2011) by increasing related gene expression during the ripening season (Castellarin et al. 2007a, b; Deluc et al. 2009). However, both mixed infection with GLRaV-3, 5, and 9 (Brar et al. 2008) and single infection with GLRaV-3 (Vega et al. 2011) had negative impacts on anthocyanin accumulation in berry skin via the down-regulation of several key genes. In our study, GLRaV-3 increased both the categories (Fig. 4) and the content (Fig. 5) of anthocyanin, effects that were further enhanced with drought stress. There was also a strong genetic component, as each grape cultivar had its own specific anthocyanin pattern (Arozarena et al. 2002; Dimitrovska et al. 2011). Gutha et al. (2010) were the few researchers who examined changes in anthocyanin content and expression levels of certain genes in GLRaV-3-infected grapevine leaves. Unfortunately, although the mutual occurrence of drought

Table 4. Two-way MANOVA of the effects of GLRaV-3 and PEG-induced drought stress on the expression levels of the 11 genes involved in anthocyanin biosynthesis pathway in leaves of in vitro plantlets of 'Cabernet Sauvignon' grapevine (Vitis vinifera)

\begin{tabular}{|c|c|c|c|c|c|c|c|}
\hline Effect & Testing methods & Value & $\mathbf{F}$ & Hypothesis df a & Error df & $\mathbf{P}^{\mathbf{b}}$ & $\overline{\text { Partial eta squared }}$ \\
\hline \multirow[t]{4}{*}{ Intercept } & Pillai's trace & 0.994 & 200 & 11 & 14 & $* *$ & 0.994 \\
\hline & Wilks' lambda & 0.006 & 200 & 11 & 14 & $* *$ & 0.994 \\
\hline & Hotelling's trace & 157 & 200 & 11 & 14 & $* *$ & 0.994 \\
\hline & Roy's largest root & 157 & 200 & 11 & 14 & $* *$ & 0.994 \\
\hline \multirow[t]{4}{*}{ Virus } & Pillai's trace & 0.993 & 177 & 11 & 14 & $* *$ & 0.993 \\
\hline & Wilks' lambda & 0.007 & 177 & 11 & 14 & $* *$ & 0.993 \\
\hline & Hotelling's trace & 139 & 177 & 11 & 14 & $* *$ & 0.993 \\
\hline & Roy's largest root & 139 & 177 & 11 & 14 & $* *$ & 0.993 \\
\hline \multirow[t]{4}{*}{ Drought } & Pillai's trace & 0.993 & 172 & 11 & 14 & $* *$ & 0.993 \\
\hline & Wilks' lambda & 0.007 & 172 & 11 & 14 & ** & 0.993 \\
\hline & Hotelling's trace & 135 & 172 & 11 & 14 & $* *$ & 0.993 \\
\hline & Roy's largest root & 135 & 172 & 11 & 14 & $* *$ & 0.993 \\
\hline \multirow[t]{4}{*}{ Virus-drought } & Pillai's trace & 0.992 & 155 & 11 & 14 & $* *$ & 0.992 \\
\hline & Wilks' lambda & 0.008 & 155 & 11 & 14 & $* *$ & 0.992 \\
\hline & Hotelling's trace & 121.592 & 155 & 11 & 14 & $* *$ & 0.992 \\
\hline & Roy's largest root & 121.592 & 155 & 11 & 14 & $* *$ & 0.992 \\
\hline
\end{tabular}

a The degrees of freedom used to obtain the observed significance level.

b $* *=$ Significant differences at $P \leq 0.01$.

Table 5. The Spearman's correlation coefficients among the expression of the 11 genes and their corresponding anthocyanin contents in leaves of in vitro plantlets of 'Cabernet Sauvignon' grapevine (Vitis vinifera) ${ }^{\mathrm{a}}$

\begin{tabular}{|c|c|c|c|c|c|c|c|c|c|c|c|c|}
\hline Variables & CHS2 & CHS3 & CHI1 & F3' $^{\prime} \mathbf{H}$ & F3' $^{\prime}{ }^{\prime} \mathbf{H}$ & F3H1 & F3H2 & DFR & LDOX & UFGT & MYBA1 & $\overline{A C^{b}}$ \\
\hline CHS2 & 1 & & & & & & & & & & & \\
\hline CHS3 & 0.367 & 1 & & & & & & & & & & \\
\hline CHI1 & 0.185 & $0.810 * *$ & 1 & & & & & & & & & \\
\hline $\mathrm{F}^{\prime}{ }^{\prime} \mathrm{H}$ & $0.420^{*}$ & $0.826^{* *} *$ & $0.854 * *$ & 1 & & & & & & & & \\
\hline $\mathrm{F}^{\prime} 5^{\prime} \mathrm{H}$ & $0.664 * *$ & $0.830 * *$ & $0.631^{* *}$ & $0.821 * *$ & 1 & & & & & & & \\
\hline F3H1 & 0.262 & $0.928 * *$ & $0.890^{*}$ & $0.868^{* *}$ & $0.721^{* *}$ & 1 & & & & & & \\
\hline $\mathrm{F} 3 \mathrm{H} 2$ & 0.365 & $0.883 * *$ & $0.874 * *$ & $0.903 * *$ & $0.732^{* *}$ & $0.938 * *$ & 1 & & & & & \\
\hline DFR & 0.182 & $0.926 * *$ & $0.878 * *$ & $0.845^{* *}$ & $0.714^{* *}$ & $0.972 * *$ & $0.912 * *$ & 1 & & & & \\
\hline LDOX & 0.16 & $0.706^{* *}$ & $0.780 * *$ & $0.762 * *$ & $0.556^{* *}$ & $0.732 * *$ & $0.749 * *$ & $0.738 * *$ & 1 & & & \\
\hline UFGT & $0.587 * *$ & 0.336 & 0.253 & $0.383^{*}$ & $0.484^{* *}$ & 0.297 & $0.418^{*}$ & 0.281 & 0.279 & 1 & & \\
\hline MYBA1 & 0.367 & 0.281 & 0.243 & $0.380^{*}$ & $0.401 *$ & 0.261 & 0.365 & 0.242 & $0.432 *$ & $0.892 * *$ & 1 & \\
\hline $\mathrm{AC}$ & $0.430 *$ & 0.019 & -0.101 & 0.042 & 0.231 & -0.073 & 0.061 & -0.079 & 0.044 & $0.801 * *$ & $0.759 * *$ & 1 \\
\hline
\end{tabular}

$\mathrm{a} *=$ Correlation is significant at the 0.05 level (2-tailed); $* *=$ correlation is significant at the 0.01 level (2-tailed).

${ }^{\mathrm{b}} \mathrm{AC}=$ anthocyanin contents. 
stress and virus infection is common in viticultural regions, it is difficult to study the two factors simultaneously in the field due to other uncontrolled variables such as light, temperature, nutrient levels, pests, and pathogens. The in vitro cultural system we used provided a stable, reliable, and controlled environment to study the effects of a single virus strain and drought stress on anthocyanin content and related gene expression levels in grapevine leaves.

Our study was unique in its discovery that GLRaV-3 increased the number of detectable anthocyanin categories. The 11 categories of anthocyanin found in the virus-infected without PEG stress and virus-infected with PEG stress treatments were similar to the 15 anthocyanin categories found in the same cultivar Cabernet Sauvignon by Mori et al. (2007), resulting in a similar pattern with five major 3 -glucoside derivatives of delphinidin, cyanidin, petunidin, peonidin, and malvidin. The missing four anthocyanin categories compared with Mori et al. (2007) may have been caused by the differences of position and stage of the samples tested and the experimental conditions. Only two major anthocyanins, cyanidin-3-glucoside and malvidin-3-glucoside, were detected in the GLRaV-3-infected leaves of 'Merlot' (Gutha et al. 2010), which may support the assertion that genetics plays a large role in the patterns of anthocyanin accumulation (Arozarena et al. 2002; Dimitrovska et al. 2011).

We found that GLRaV-3 infection had a major role in anthocyanin accumulation, while the combination of drought stress with GLRaV3 infection had an even greater impact on the accumulation of anthocyanins. Previous studies found that drought stress can increase anthocyanin content of grape berries (Castellarin et al. 2007a, b; Deluc et al. 2009), and that regulated-deficit irrigation can increase the anthocyanin content of berries and wine (Chapman et al. 2005; Roby et al. 2004). However, GLD has an adverse role in anthocyanin accumulation in berries (Brar et al. 2008; Vega et al. 2011). In Vitis, it is known that anthocyanin levels increase concomitantly with sugar accumulation (Coombe 1992; Deluc et al. 2009; Vitrac et al. 2000), and a reduction in sugar concentrations was related to anthocyanin decreases in GLRaV-3-infected berries (Vega et al. 2011). Infections by other viruses, such as PVY and PLRV in potato (Li et al. 2013), have also been found to act like GLRaV-3 in grape (Espinoza et al. 2007) and cause increases in leaf sugar concentrations. A possible explanation for the anthocyanin accumulation could be the increased sugar content in the leaves. Gutha et al. (2010) found that leafroll virus infection increased the anthocyanin content of 'Merlot' leaves, which is consistent with our results. Although there are no other reports examining the combined impact of virus and drought on anthocyanin accumulation in leaves to support our results, we believe that drought stress enhances the effect of GLRaV-3 infection on anthocyanin accumulation in grape leaves, given the results of our four treatments on anthocyanin content.

The expression of genes from upstream pathways can affect the expression pattern of downstream genes, and regulatory genes can affect corresponding structural genes (Wethmar 2014). These intricate relationships contribute to a complicated expression pattern of the anthocyanin biosynthesis pathway and affect the accumulation of its products. Increased anthocyanin accumulation was induced by the up-regulation of genes involved in both drought stress (Castellarin et al. 2007a, b; Deluc et al. 2009) and GLD stress (Gutha et al. 2010; Vega et al. 2011). The genes of the anthocyanin biosynthesis pathway analyzed in this study were all up-regulated by drought stress (except UFGT and MYBA1), GLRaV-3 infection, and its combination with drought stress (Fig. 8). However, the impact of drought stress alone on gene expression was not as well supported by leaf phenotypes (Fig. 3) or by its anthocyanin categories (Fig. 4) and contents (Fig. 5); GLRaV-3 infection had a greater impact than drought stress on the anthocyanin accumulation in leaves (Table 3). When stressed only by drought, the expression levels of CHS2, CHS3, CHI1, F3'H, F3'5' H, F3H1, F3H2, DFR, and LDOX were at a higher level compared with the response due to GLRaV-3 infection (Fig. 8). However, GLRaV-3 infection had a large impact on up-regulating the expression level of UFGT and MYBA1 (Fig. 8). It is well known that UFGT triggers anthocyanin biosynthesis (Kobayashi et al. 2001) and that MYBA1 controls the expression of UFGT (Kobayashi et al.
2002; Walker et al. 2007). Our results also support these interactions with strong correlations among UFGT and MYBA1 expression levels and anthocyanin contents (Table 5). A negative or lower correlation between anthocyanin accumulation and the expression levels of other genes (CHS3, CHI1, F3'H, F3'5'H, F3H1, F3H2, DFR, LDOX) was due to the early triggered expression pattern of these genes, while the anthocyanin accumulation kept increasing during the whole culture period. The delivery of MYBA1 to a noncolored embryo led to the induction of reddish-purple spots and UFGT expression (Kobayashi et al. 2002), also indicating the importance of MYBA1 and UFGT in anthocyanin accumulation. Now, it is unambiguous that MYBA1 and UFGT are two limiting factors in the anthocyanin accumulation in the leaves of 'Cabernet Sauvignon' in vitro plantlets, which could be activated by GLRaV-3 infection. However, it is noteworthy that all the genes involved in the biosynthesis pathway are necessary and important in the anthocyanin accumulation, but their roles vary due to the spatial and temporal specificity of their expression, which also are affected by different stresses and experimental conditions.

Many studies are currently focused on the regulation of miRNA in plant development and metabolism. miRNA156 (Gou et al. 2011) and miRNA828 (Yang et al. 2013) were found to mediate the accumulation of anthocyanin. In grapevine, virus-infection was found to alter miRNA profiling, including up and down regulation and induction of novel miRNAs (Alabi et al. 2012; Singh et al. 2012). However, it remains to further prove whether the changes in anthocyanin accumulation caused by virus infection in grape leaves and berries are mediated by miRNA. Studies examining these interactions with miRNA are currently under investigation.

\section{Conclusion}

In this study, we investigated the effects of drought stress and GLRaV-3 infection on anthocyanin accumulation and found GLRaV3 infection acts as the determining factor in increasing anthocyanin accumulation by magnifying the expression levels of two key genes, UFGT and MYBA1. We also found that the impact of drought stress further enhanced anthocyanin accumulation in the leaves of in vitro plantlets of 'Cabernet Sauvignon' grapevine when coupled with GLRaV-3 infection. These findings have implications for the rapid production of anthocyanins and for determining how GLD expression might be controlled in infected grapevines. The next steps in this study will employ miRNA analysis to help fully elucidate the impacts of virus and drought on anthocyanin production.

\section{Acknowledgments}

The authors gratefully acknowledge financial supports through "948" program from State Forestry Administration of China (project no. 2013-4-41) and through from Department of Science \& Technology of Shaanxi Province of China (project no. 2013KTCL02-01).

\section{Literature Cited}

Alabi, O. J., Yun, Z., Jagadeeswaran, G., Sunkar, R., and Naidu, R. A. 2012. Highthroughput sequence analysis of small RNAs in grapevine (Vitis vinifera) affected by grapevine leafroll disease. Mol. Plant Pathol. 13:1060-1076.

Arozarena, I., Ayestera'n, B., Cantalejo, M. J., Navarro, M., Vera, M., Abril, I., and Casp, A. 2002. Anthocyanin composition of Tempranillo, Garnacha and Cabernet Sauvignon grapes from high- and low-quality vineyards over two years. Eur. Food Res. Technol. 214:303-309.

Berdeja, M., Hilbert, G., Dai, Z. W., Lafontaine, M., Stoll, M., Schultz, H. R., and Delrot, S. 2014. Effect of water stress and rootstock genotype on Pinot Noir berry composition. Aust. J. Grape Wine Res. 20:409-421.

Bester, R., Pepler, P. T., Burger, J. T., and Maree, H. J. 2014. Relative quantitation goes viral: An RT-qPCR assay for a grapevine virus. J. Virol. Methods 210:67-75.

Booij-James, I. S., Dube, S. K., Jansen, M. A., Edelman, M., and Mattoo, A. K. 2000. Ultraviolet-B radiation impacts light-mediated turnover of the photosystem II reaction center heterodimer in Arabidopsis mutants altered in phenolic metabolism. Plant Physiol. 124:1275-1284.

Brar, H. S., Singh, Z., Swinny, E., and Cameron, I. 2008. Girdling and grapevine leafroll-associated viruses affect berry weight, colour development and accumulation of anthocyanins in 'Crimson Seedless' grapes during maturation and ripening. Plant Sci. 175:885-897.

Bucchetti, B., Matthews, M. A., Falginella, L., Peterlunger, E., and Castellarin, S. D. 2011. Effect of water deficit on Merlot grape tannins and anthocyanins across four seasons. Sci. Hortic. (Amsterdam) 128:297-305. 
Castellarin, S. D., Di Gaspero, G., Marconi, R., Nonis, A., Peterlunger, E., Paillard, S., Adam-Blondon, A. F., and Testolin, R. 2006. Colour variation in red grapevines (Vitis vinifera L.): genomic organisation, expression of flavonoid 3'-hydroxylase, flavonoid 3',5'-hydroxylase genes and related metabolite profiling of red cyanidin-/blue delphinidin-based anthocyanins in berry skin. BMC Genomics 7:12.

Castellarin, S. D., Matthews, M. A., Gaspero, G. D., and Gambetta, G. A. 2007a. Water deficits accelerate ripening and induce changes in gene expression regulating flavonoid biosynthesis in grape berries. Planta 227:101-112.

Castellarin, S. D., Pfeiffer, A., Sivilotti, P., Degan, M., Peterlunger, E., and Gaspero, G. D. 2007b. Transcriptional regulation of anthocyanin biosynthesis in ripening fruits of grapevine under seasonal water deficit. Plant Cell Environ. 30:1381-1399.

Chalker-Scott, L. 1999. Environmental significance of anthocyanins in plant stress responses. Photochem. Photobiol. 70:1-9.

Chapman, D. M., Roby, G., Ebeler, S. E., Guinard, J. X., and Matthews, M. A. 2005. Sensory attributes of Cabernet Sauvignon wines made from vines with different water status. Aust. J. Grape Wine Res. 11:339-347.

Chen, C. S., Zhang, D., Wang, Y. Q., Li, P. M., and Ma, F. W. 2012. Effects of fruit bagging on the contents of phenolic compounds in the peel and flesh of 'Golden Delicious', 'Red Delicious', and 'Royal Gala' apples. Sci. Hortic. (Amsterdam) 142:68-73.

Coombe, B. G. 1992. Research on development and ripening of the grape berry. Am. J. Enol. Vitic. 43:101-110.

Cui, Z. H., Bi, W. L., Hao, X. Y., Xu, Y., Li, P. M., Walker, M. A., and Wang, Q. C. 2016. Responses of in vitro-grown plantlets (Vitis vinifera) to Grapevine leafroll-associated virus-3 and PEG-induced drought stress. Front. Physiol. 7: 203.

Cui, Z. H., Bi, W. L., Pan, C., Xu, Y., and Wang, Q. C. 2015. Abiotic stress improves in vitro biological indexing of Grapevine leafroll-associated virus3 in red grapevine cultivars. Aust. J. Grape Wine Res. 21:490-495.

Deluc, L., Bogs, J., Walker, A. R., Ferrier, T., Decendit, A., Merillon, J. M., Robinson, S. P., and Barrieu, F. 2008. The transcription factor VvMYB5b contributes to the regulation of anthocyanin and proanthocyanidin biosynthesis in developing grape berries. Plant Physiol. 147:2041-2053.

Deluc, L. G., Quilici, D. R., Decendit, A., Grimplet, J., Wheatley, M. D., Schlauch, K. A., Mérillon, J. M., Cushman, J. C., and Cramer, G. R. 2009. Water deficit alters differentially metabolic pathways affecting important flavor and quality traits in grape berries of Cabernet Sauvignon and Chardonnay. BMC Genomics 10:212.

Dimitrovska, M., Bocevska, M., Dimitrovski, D., and Murkovic, M. 2011. Anthocyanin composition of Vranec, Cabernet Sauvignon, Merlot and Pinot Noir grapes as indicator of their varietal differentiation. Eur. Food Res. Technol. 232:591-600.

Dixon, R. A., and Paiva, N. L. 1995. Stress-induced phenylpropanoid metabolism. Plant Cell 7:1085-1097.

Espinoza, C., Medina, C., Somerville, S., and Arce-Johnson, P. 2007. Senescenceassociated genes induced during compatible viral interactions with grapevine and Arabidopsis. J. Exp. Bot. 58:3197-3212.

Faraloni, C., Cutino, I., Petruccelli, R., Leva, A. R., Lazzeri, S., and Torzillo, G. 2011. Chlorophyll fluorescence technique as a rapid tool for in vitro screening of olive cultivars (Olea europaea L.) tolerant to drought stress. Environ. Exp. Bot. 73:49-56.

Georgiev, V., Anthony-Ananga, A., and Tsolova, V. 2014. Recent advances and uses of grape flavonoids as nutraceuticals. Nutrients 6:391-415.

Goto-Yamamoto, N., Wan, G. H., Masaki, K., and Kobayashi, S. 2002. Structure and transcription of three chalcone synthase genes of grapevine (Vitis vinifera). Plant Sci. 162:867-872.

Gou, J. Y., Felippes, F. F., Liu, C. J., Weigel, D., and Wang, J. W. 2011. Negative regulation of anthocyanin biosynthesis in arabidopsis by a miRNA156-targeted spl transcription factor. Plant Cell 23:1512-1522.

Gould, K. S., and Lister, C. 2006. Flavonoid function in plants. Pages 397-411 in: Flavonoids: Chemistry, Biochemistry and Applications. M. Andersen and K. R. Markham, eds. CRC Press, Boca Raton, FL.

Gutha, L. R., Casassa, L. F., Harbertson, J. F., and Naidu, R. A. 2010. Modulation of flavonoid biosynthetic pathway genes and anthocyanins due to virus infection in grapevine (Vitis vinifera $\mathrm{L}$.) leaves. BMC Plant Biol. 10:187.

Hao, H. X., Bi, W. L., Cui, Z. H., Pan, C., Xu, Y., and Wang, Q. C. 2017. Development, histological observations and Grapevine leafroll-associated virus-3 localization of in in vitro grapevine micrografts. Ann. Appl. Biol. 170:379-390.

Hichri, I., Barrieu, F., Bogs, J., Kappel, K., Delrot, S., and Lauvergeat, V. 2011. Recent advances in the transcriptional regulation of the flavonoid biosynthetic pathway. J. Exp. Bot. 62:2465-2483.

Holton, T. A., and Cornish, E. C. 1995. Genetics and biochemistry of anthocyanin biosynthesis. Plant Cell 7:1071-1083.

Intrigliolo, D. S., Pérez, D., Risco, D., Yeves, A., and Castel, J. R. 2012. Yield components and grape composition responses to seasonal water deficits in Tempranillo grapevines. Irrig. Sci. 30:339-349.

Jeong, S. T., Goto-Yamamoto, N., Kobayashi, S., and Esaka, M. 2004. Effects of plant hormones and shading on the accumulation of anthocyanins and the expression of anthocyanin biosynthetic genes in grape berry skins. Plant Sci. $167: 247-252$.
Kennedy, J. A., Hayasaka, Y., Vidal, S., Waters, E. J., and Jones, G. P. 2001. Composition of grape skin proanthocyanidins at different stages of berry development. J. Agric. Food Chem. 49:5348-5355.

Kidd, P. S., Llugany, M., Poschenrieder, C., Gunsé, B., and Barceló, J. 2001. The role of root exudates in aluminium resistance and silicon-induced amelioration of aluminium toxicity in three variety of maize (Zea mays L.). J. Exp. Bot. 52: $1339-1352$.

Kobayashi, S., Ishimaru, M., Ding, C. K., Yakushiji, H., and Goto, N. 2001 Comparison of UDP-glucose:flavonoid 3-O-glucosyltransferase (UFGT) gene sequences between white grapes (Vitis vinifera) and their sports with red skin. Plant Sci. 160:543-550.

Kobayashi, S., Ishimaru, M., Hiraoka, K., and Honda, C. 2002. Myb-related genes of the Kyoho grape (Vitis labruscana) regulate anthocyanin biosynthesis. Planta 215:924-933.

Koes, R., Verweij, W., and Quattrocchio, F. 2005. Flavonoids: a colorful model for the regulation and evolution of biochemical pathways. Trends Plant Sci. 10 236-242.

Landry, L. G., Chapple, C. C. S., and Last, R. L. 1995. Arabidopsis mutants lacking phenolic sunscreens exhibit enhanced ultraviolet-B injury and oxidative damage. Plant Physiol. 109:1159-1166.

Li, J. W., Wang, B., Song, X. M., Wang, R. R., Chen, L., Zhang, H., Zhang, Z. B., and Wang, Q. C. 2013. Potato leafroll virus (PLRV) and Potato virus $Y$ (PVY) influence vegetative, physiological metabolism of in vitro-cultured shoots of potato (Solanum tuberosum L.). Plant Cell Tiss. Org. Cult. 114 313-324.

Liu, M. H., Li, M. J., Qi, H. H., Guo, R., Liu, X. M., and Wang, Q. 2013 Occurrence of grapevine leafroll-associated viruses in China. Plant Dis. 97:1339-1345

Livak, K. J., and Schmittgen, T. D. 2001. Analysis of relative gene expression data using real-time quantitative PCR and the 2(-Delta Delta C (T)) method. Methods 25:402-408.

Maree, H. J., Almeida, R. P. P., Bester, R., Chooi, K. M., Cohen, D., Dolja, V. V., Fuchs, M. F., Golino, D. A., Jooste, A. E. C., Martelli, G. P., Naidu, R. A Rowhani, A., Saldarelli, P., and Burger, J. T. 2013. Grapevine leafrollassociated virus 3. Front. Microbiol. 4:138-158.

Menzel, W., Jelkmann, W., and Maiss, E. 2002. Detection of four apple viruses by multiplex RT-PCR assays with coamplification of plant mRNA as internal control. J. Virol. Methods 99:81-92.

Mori, K., Goto-Yamamoto, N., Kitayama, M., and Hashizume, K. 2007. Loss of anthocyanins in red-wine grape under high temperature. J. Exp. Bot. 58: 1935-1945

Murashige, T., and Skoog, F. 1962. A revised medium for rapid growth and bioassays with tobacco cell cultures. Physiol. Plant. 15:473-497.

Ollé, D., Guiraud, J. L., Souquet, J. M., Terrier, N., Ageorges, A., Cheynier, V., and Verries, C. 2011. Effect of pre- and post-veraison water deficit on proanthocyanidin and anthocyanin accumulation during Shiraz berry development. Aust. J. Grape Wine Res. 17:90-100.

Osman, F., and Rowhani, A. 2006. Application of a spotting sample preparation technique for the detection of pathogens in woody plants by RT-PCR and real-time PCR (TaqMan). J. Virol. Methods 133:130-136.

Roby, G., Harbertson, J. F., Adams, D. A., and Matthews, M. A. 2004. Berry size and vine water deficits as factors in winegrape composition: anthocyanins and tannins. Aust. J. Grape Wine Res. 10:100-107.

Santesteban, L. G., Miranda, C., and Royo, J. B. 2011. Regulated deficit irrigation effects on growth, yield, grape quality and individual anthocyanin composition in Vitis vinifera L. cv. 'Tempranillo'. Agric. Water Manage. 98:1171-1179.

Singh, K., Talla, A., and Qiu, W. 2012. Small RNA profiling of virus-infected grapevines: evidences for virus infection-associated and variety-specific miRNAs. Funct. Integr. Genomics 12:659-669.

Tanne, E., Spiegel-Roy, P., and Shlamovitz, N. 1996. Rapid in vitro indexing of grapevine viral diseases: the effect of stress-inducing agents on the diagnosis of leafroll. Plant Dis. 80:972-974.

Vega, A., Gutiérrez, R. A., Peña-Neira, A., Cramer, G. R., and Arce-Johnson, P. 2011. Compatible GLRaV-3 viral infections affect berry ripening decreasing sugar accumulation and anthocyanin biosynthesis in Vitis vinifera. Plant Mol. Biol. 77:261-274.

Vitrac, X., Larronde, F., Krisa, S., Decendit, A., Deffieux, G., and Merillon, J. M 2000. Sugar sensing and $\mathrm{Ca}^{2+}$-calmodulin requirement in Vitis vinifera cells producing anthocyanins. Phytochem. 53:659-665.

Walker, A., Lee, E., Bogs, J., McDavid, D., Thomas, M., and Robinson, S. 2007. White grapes arose through the mutation of two similar and adjacent regulatory genes. Plant J. 49:772-785.

Wethmar, K. 2014. The regulatory potential of upstream open reading frames in eukaryotic gene expression. Wiley Interdiscip. Rev. RNA 5:765-768.

Winkel-Shirley, B. 2001. Flavonoid biosynthesis. A colorful model for genetics, biochemistry, cell biology, and biotechnology. Plant Physiol. 126:485-493.

Yamane, T., Jeong, S. T., Goto-Yamamoto, N., Koshita, Y., and Kobayashi, S 2006. Effects of temperature on anthocyanin biosynthesis in grape berry Skins. Am. J. Enol. Vitic. 57:54-59.

Yang, F. X., Cai, J., Yang, Y., and Liu, Z. B. 2013. Overexpression of microRNA828 reduces anthocyanin accumulation in Arabidopsis. Plant Cell Tiss. Org. Cult. 115:159-167. 